
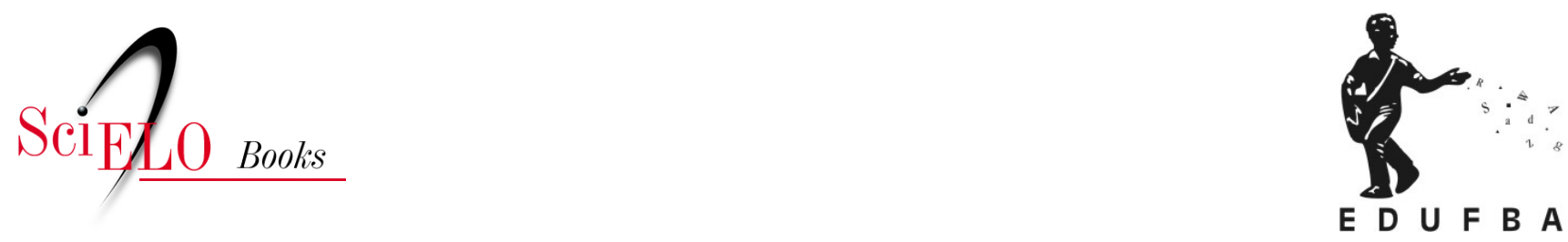

\title{
Pensar por redes
}

\author{
Rodrigo de Faria
}

\section{SciELO Books / SciELO Livros / SciELO Libros}

FARIA, R. Pensar por redes. In: JACQUES, P.B., and PEREIRA, M.S., comps. Nebulosas do pensamento urbanístico: tomo I - modos de pensar [online]. Salvador: EDUFBA, 2018, pp. 288-330. ISBN 978-85232-2032-7. https://doi.org/10.7476/9788523220327.0012.

All the contents of this work, except where otherwise noted, is licensed under a Creative Commons Attribution 4.0 International license.

Todo o conteúdo deste trabalho, exceto quando houver ressalva, é publicado sob a licença Creative Commons Atribição $\underline{4.0}$. 
PENSA R PO R 


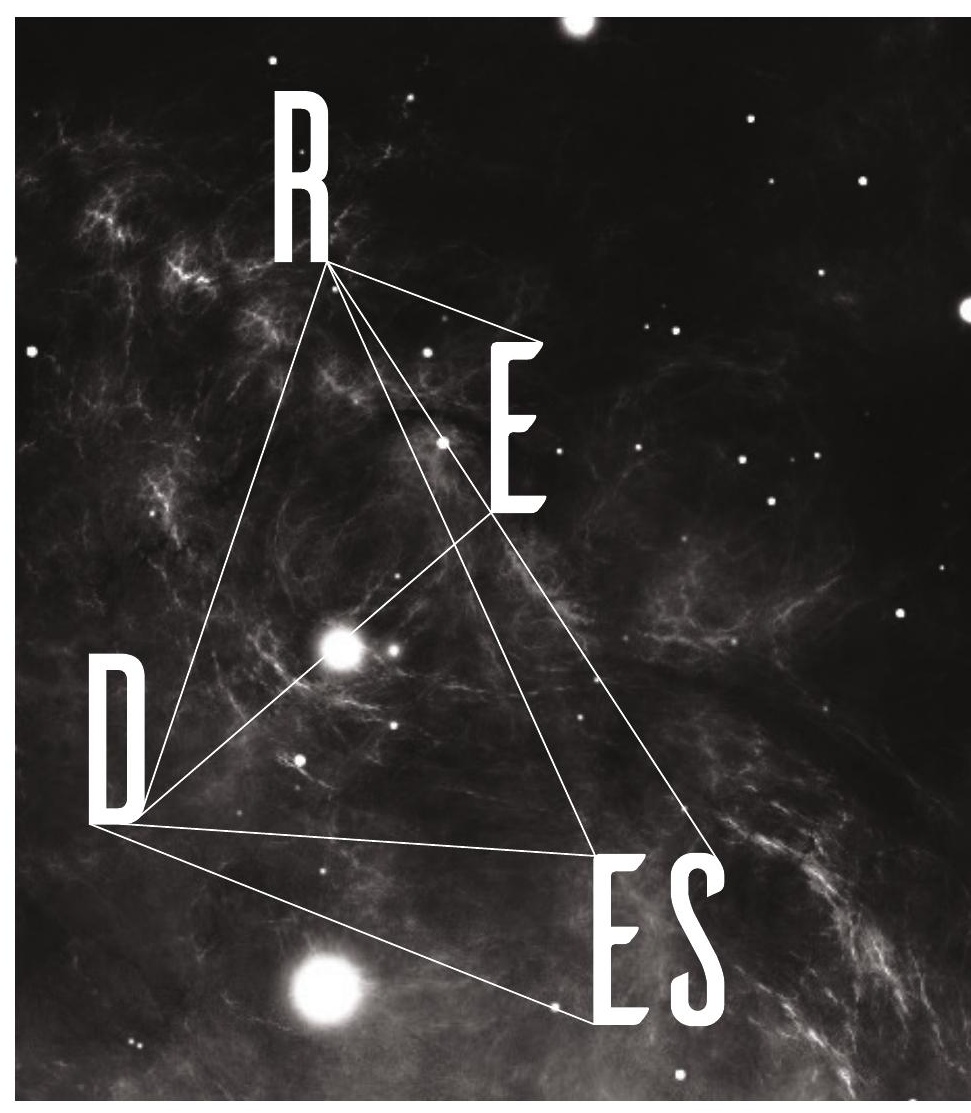




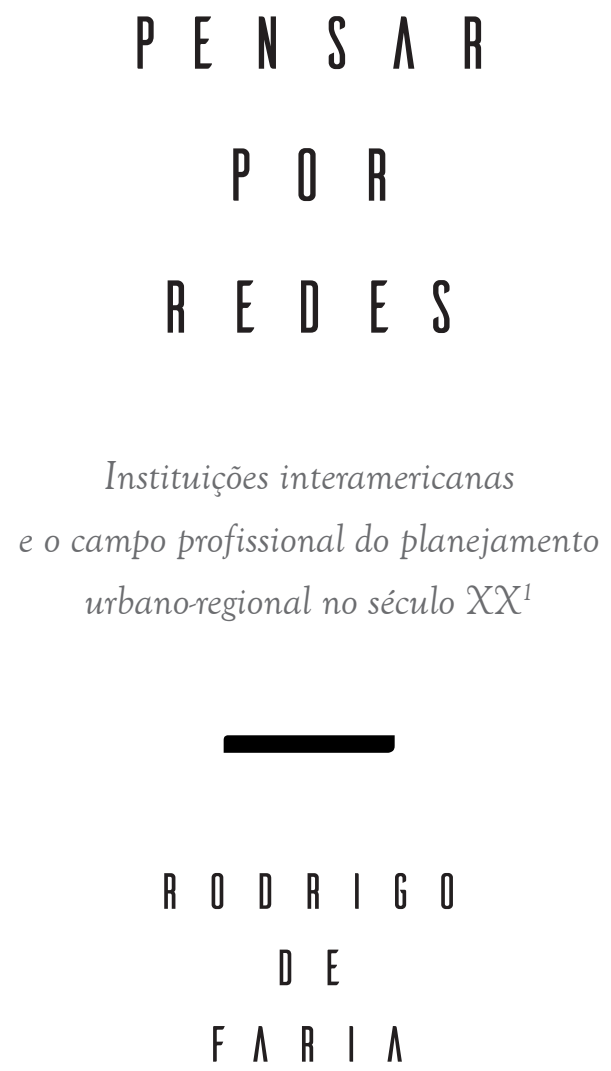




\section{Pensar Por Redes:}

\section{ALGUMAS CONSIDERAÇÕES CONCEITUAIS}

as páginas iniciais da coletânea Urbanismo na América do Sul: circulação das ideias e constituição do campo, publicada em 2009, constam algumas considerações importantes e ainda oportunas para a ideia de "pensar por redes". Da mesma forma, é necessário ressaltar que tais considerações foram antecedidas por uma observação igualmente importante sobre a persistência de lacunas nas discussões produzidas pela área de arquitetura e urbanismo, ainda que reconhecendo os avanços nas pesquisas relativas à história da cidade e do urbanismo. (GOMES, 2009, p. 7) Com base nesse argumento sobre a persistência das lacunas, seria possível enveredar a análise para um debate concernente à condição lacunar da história e como isso orientaria a sua escrita - na mesma perspectiva da escrita da história formulada por Paul Veyne - ou o que seria o seu avesso, as concepções totalizantes.

Dado que esse exercício mais conceitual sobre a escrita da história foi realizado em dois estudos publicados, ${ }^{2}$ o movimento analítico ficará concentrado nas considerações enunciadas na referida coletânea. A primeira delas informa que os textos publicados permitem "rastrear o surgimento de redes profissionais, mapear discussões, identificar caminhos e descaminhos 
da construção de uma cultura urbanística continental”. (GOMES, 2009 , p. 7) A segunda consideração está atrelada ao conjunto de perguntas sobre o papel dos congressos profissionais no debate urbanístico, sobre a circulação de informações dos países do continente e sobre como os profissionais viam suas próprias realizações. A partir dessas indagações e reconhecendo que as redes de relações com o contexto europeu - especialmente um profissional, Le Corbusier, e uma organização, os Congressos Internacionais da Arquitetura Moderna (CIAM) - já eram bem conhecidas, enunciou-se que, por outro lado, "as eventuais redes profissionais de circulação de ideias no âmbito continental são tema ainda pouco explorado pela bibliografia, particularmente a brasileira". 3 (GOMES, 2009, p. 14-15)

Tendo em vista que a coletânea Urbanismo na América do Sul foi publicada há quase dez anos, convém ressaltar que, de certa forma, um movimento para ampliar e consolidar certo esforço exploratório e, assim, aproximar a pesquisa brasileira dos estudos em história urbana-urbanística produzidos no continente americano (especialmente sua parte hispano-americana) foi iniciado e está em processo - ainda que não necessariamente orientado para o estudo dessas redes. As duas últimas edições do Seminário Urbanistas e Urbanismo no Brasil, realizadas no Instituto de Arquitetura e Urbanismo (IAU) da Universidade de São Paulo (USP) em 2015 e na Universidade Federal de Pernambuco (UFPE) em 2017; o I Seminário do Grupo de Pesquisa Cultura, Arquitetura e Cidade na América Latina (CACAL), da Faculdade de Arquitetura e Urbanismo da USP, realizado no ano de 2017; os Encontros Internacionais Cidades Latino-americanas do Grupo de Estudos do Território e de História Urbana (GETHU) do Instituto de Pesquisa e Planejamento Urbano e Regional (IPPUR) da Universidade Federal do Rio de Janeiro (UFRJ), realizados desde 2006; os Dossiês da Revista URBANA do Centro Interdisciplinar de Estudos sobre a Cidade (CIEC) da Universidade Estadual de Campinas (UNICAMP) dedicados à América Latina; entre outros movimentos, indicam que a pesquisa brasileira está no caminho para reverter o diagnóstico crítico ${ }^{4}$ da coletânea Urbanismo na América do Sul.

Entre os textos publicados nessa coletânea, aponto dois que indicam 292 dois grandes contextos espacial-intelectuais de diálogo entre os 
urbanistas que atuaram no continente, sobretudo na primeira década do século XX: o primeiro elaborado por Fernando Atique e denominado "Articulações profissionais: os Congressos Panamericanos de Arquitetos e o amadurecimento de uma profissão no Brasil, 1920-1940"; o segundo elaborado por Eloísa Petti Pinheiro e denominado "Circulação de ideias e academicismo: os projetos urbanos para as capitais do Cone Sul, entre 1920 e 1940”. De alguma forma, ambos estão trabalhando com redes; o primeiro, de Fernando Atique, inclusive numa importante aproximação com os debates políticos sobre a própria concepção e historicidade da ideia de "pan-americanismo".

O primeiro texto enuncia a construção de uma rede de debates atrelados aos Congressos Pan-americanos de Arquitetos. Nesse sentido, é mais centrado numa análise sobre um certo "processo endógeno continental" de construção de ideias e proposições marcadamente orientadas pelo protagonismo dos profissionais uruguaios a partir da criação, em 1914, da Sociedad Central de Arquitetos del Uruguai. O segundo texto também explicita o movimento de construção de ideias e proposições, mas marcadamente um "processo exógeno", pautado pela circulação de profissionais europeus que elaboraram planos e projetos para as cidades do Rio de Janeiro, Buenos Aires, Montevidéu e Santiago do Chile. E segundo Eloisa Petti Pinheiro (2009, p. 120), essa circulação intelectual-profissional foi caracterizada por um aspecto particular: "[...] a maioria dos projetos apresentados para as cidades sul-americanas ainda reflete as tradições Beaux-Arts”.

Esses dois enunciados (endógenos e exógenos) que estou utilizando para diferenciar os dois textos exigem uma explicação. A intenção aqui não é a de recair na narrativa explicativa da "importação das ideias", muito utilizada na historiografia brasileira e hispano-americana, especialmente quando se trata das relações que envolvem os profissionais e as experiências urbanísticas europeias para elucidar os acontecimentos do lado de cá do Atlântico. E como já afirmou Stella Bresciani (2012, p. 155), e eu corroboro com sua visão crítica, a "[...] fórmula da 'europeização', da 'haussmanização' de várias cidades”, no âmbito da pesquisa em arquitetura e urbanismo, é comum no Brasil. $\mathrm{O}$ uso desses dois enunciados tem como objetivo apenas demarcar os 
movimentos profissionais que, em cada um dos dois textos, estruturam o eixo central da análise: o de Fernando Atique pelos profissionais do continente americano, o de Eloisa Pinheiro pelos profissionais do continente europeu. Tanto não corroboro com as explicações estruturadas pela noção de "importação" que, novamente, me apoio nos argumentos de Stella Bresciani (2012, p. 158), que enunciou ser importante

[...] aceitar o desafio de explorar criticamente a ampla circulação de ideias, modelos, tipologias e práticas bem ou malsucedidas, como a base de nossas pesquisas e da leitura dos documentos produzidos em diferentes linguagens. $\mathrm{O}$ intuito é mostrar a importância de não se aprisionar a reflexão ou as respostas às questões levantadas a uma implicação ou interpretação a priori sempre apoiada em modelos facilitadores de análise. Proponho aceitar não terem as noções e conceitos do urbanismo um lugar fisicamente definível - país, cidade, escritos de um único profissional, mas se disporem em livros, revistas e demais suportes - e, comporem um amplo e complexo campo de conhecimento estruturado no evidente intercâmbio entre profissionais da área, do campo não estável e cristalizado, e sujeito à transitoriedade das ideias, à contingência de suas aplicações, à polissemia de seu vocabulário, aos embates de interesses de ordem variada.

Esse breve percurso - e considerações sobre algumas passagens - pelo livro Urbanismo na América do Sul foi necessário por dois motivos. $\mathrm{O}$ primeiro, para reconhecer que o livro permanecerá na historiografia da cidade e do urbanismo com uma contribuição referencial às análises das redes intelectuais e profissionais. O segundo, pela constatação de que, mesmo se tratando de um trabalho que abriu uma porta de análise das redes profissionais, não consta nenhuma consideração sobre o que seriam essas redes numa dimensão mais conceitual e que, para a abordagem proposta neste artigo de "pensar por redes", é fundamental. Ainda assim, essa constatação não diminui a importância do livro, mas apenas enuncia que, desde o campo de pesquisa em arquitetura e urbanismo, praticamente não existem trabalhos com 294 entradas mais conceituais. 
Em sua maioria absoluta, esse movimento de investigação conceitual e mesmo temático - e aqui as redes intelectuais são o objeto privilegiado - é originário do campo das ciências humanas, particularmente do âmbito da história das ideias e da história intelectual. Entre os principais nomes, estão os de Eduardo Devés-Valdés (Chile), Marta Casaús Arzú (Espanha), Claudia Wasserman (Brasil), Germán Albuquerque Fuschini (Chile), Fernanda Beigel (Argentina), entre outros. Dentre eles, a contribuição de Eduardo Devés, em especial as anotações presentes no livro Redes intelectuales en America Latina: hacia la constitución de una comunidade intelectual, publicado originalmente em 2007, é fundamental. Nesse trabalho, organizado com bases em estudos que já vinham sendo desenvolvidos, o autor analisa o pensamento latino-americano entre o final do século XIX e o início do XXI com estudos sobre a rede arielista, as redes teosóficas, a Comissão Econômica para a América Latina e o Caribe (CEPAL), redes latino-americanas no Mediterrâneo.

Porém, e talvez mais importante que as análises sobre algumas das redes mapeadas pelo autor, são as duas perguntas estruturantes do seu trabalho: ¿quées una red intelectual? e ¿como y por qué se formanlas redes?, que acompanham ainda uma explicação sobre a metodologia formulada para o estudo das redes. E afinal, o que seria, então, uma rede, ou uma rede intelectual, em suas diversas dimensões, entre elas, a temporal e as situações em que as trocas e circulações (das ideias e das pessoas) ocorreram? Segundo Devés (2014, p. 30), se entende por tal:

[...] a un conjunto de personas ocupadas en la producción y difusión del concocimiento, que se comunican en razón de su actividad profesional, a lo largo de los años [...] Las formas de relación entre quienes constituyen una rede pueden ser variadas. Los encuentros cara a cara, las correspondencia a través de diversos soportes y los contactos telefónicos dan lugar a congresos, campañas, publicaciones, comentarios o reseñas de libros, citaciones recíprocas y otras tantas formas en que se establecen articulaciones en el mundo intelectual [...] La cuestión temporal es decisiva para distinguir los contactos esporádicos o casuales, de la real constitución de una red, que necessita la frecuencia o la densidade en la comunicación. La densidade permite entender cuáles son los núcleos más activos de la red, así como los momentos de mayor o menor vitalidade. 
Outro autor que também formulou uma explicação conceitual sobre o que seria uma rede foi Germán Fuschini. No artigo "La Red de Escritores Latino americanos en los Años Sesenta”, publicado na revista Universum da Universidad de Talca, dedicado à análise da construção de uma rede de escritores do continente a partir da proposta chilena de organização do Primer Encuentro de Escritores Americanos - que ocorreu em 1960 sob a coordenação de Gonzalo Rojas da Universidad de Concepción -, Fuschini apresenta a seguinte pergunta: ¿qué entiendo por una red? A resposta não difere muito em termos mais genéricos daquela acima formulada por Devés, e segundo Fuschini (2000, p. 337),

una red - intelectual, en nuestro caso sería el conjunto de relaciones que se forman entre intelectuales, o sea, entre aquelllas personas que trabajan principalmente con el intelecto, con el entendimento, y en esta categoria entran desde novelistas, poetas, ensayistas, artistas, historiadores, sociólogos, economistas hasta profesionales de diverso tipo. pues bien, una red de intelectuales se define por las relaciones que éstos establezvan entre sí, relaciones que pueden ser amistades, visitas, cartas, intercâmbios de libros, participación en un mismo congresso, coautoría de libros, trabajar en un mismo lugar, etc.

Ambas formulações ajudam na elaboração de indagações em relação ao campo de atuação de profissionais que atuaram como urbanistas e planejadores urbanos, ainda que não sejam esses os profissionais que interessam aos dois pesquisadores como objeto de pesquisa. Além disso, os autores reconhecem e afirmam que as redes são formadas por pessoas que trabalham intelectualmente, produzindo algum conhecimento. Portanto, é possível e necessário partir da ideia de que arquitetos, urbanistas, planejadores, juristas, engenheiros, entre outros profissionais, formaram redes no continente americano durante o século XX. A própria CEPAL, que é um dos objetos de estudo de Devés, é toda formada por profissionais que colaboravam com os estudos sobre o desenvolvimento latino-americano que essa instituição realizou. Estudos realizados por intelectuais cujos enunciados estavam atrelados aos seus próprios saberes profissionais de origem, ainda que, nesse contexto, com certa primazia do saber econômico, 296 representado por profissionais como o brasileiro Celso Furtado. 
Nesse ponto, faz-se necessário elaborar uma pergunta: mas o que deve ser entendido por "profissional"? Ou ainda, o que diferenciaria esse tipo de atuação intelectual denominada de "profissionais" de uma rede de escritores, por exemplo, do campo da literatura, cuja atuação também é necessariamente intelectual? A explicação e, portanto, a diferenciação também podem vir do texto Devés (2014) sobre a CEPAL, ao apresentar os propósitos dessa instituição conforme a Resolução 106 do Conselho Econômico e Social da Organização das Nações Unidas (ONU):

realizar tareas de investigación y estúdios sobre cuestiones económicas y socilaes de interés para la región; compilar, evaluar y difundir informaciones económicas, técnicas y estadísticas y estimular la cooperación com otros organismos especializados em cuestiones del desarrollo en America Latina o dentro del ámbito de la organización de las Naciones Unidas. (DEVÉS, 2014, p. 96)

Portanto, o que estou entendendo e assumindo conceitualmente como uma rede profissional é aquela cuja atuação e produção de conhecimento tem um caráter especializado - mesmo que articulando diversos saberes com uma finalidade específica - e um caráter técnico nos termos de uma determinada cultura profissional. Como exemplo, os urbanistas e a cultura profissional urbanística forjada entre final século XX e início do XXI como campo disciplinar, saber sobre a cidade ou ciência urbana, tal qual enunciado por Christian Topalov (1991). Evidentemente, não quero, com isso, afirmar que existiu uma única rede profissional no continente americano com foco de atuação no campo do planejamento urbano e regional, menos ainda que as redes cujos profissionais formularam propostas para o desenvolvimento municipal são todas oriundas das esferas profissionais da arquitetura e do urbanismo.

A partir da pesquisa em desenvolvimento sobre um conjunto de quatro instituições interamericanas criadas no século XX, cujas ações estavam, em termos gerais e segundo suas particularidades, direcionadas ao campo do planejamento, busca-se justamente iluminar a diversidade das redes interamericanas de estudos, debates e proposições urbano-regionais que, inclusive, surgiram de propósitos 
distintos e com profissionais de campos intelectuais diversos. São elas a Organización Interamerinaca de Cooperación Intermunicipal (OICI), a Sociedad Interamericana de Planificación (SIAP), o Centro Interamericano de Vivienda y Planeamiento (CINVA) e a División de Vivienda y Planeamiento da Unión Panamericana (DVPUP). Entre elas, uma, inclusive, não surgiu inicialmente para atuação no campo do planejamento, e sim da habitação: o CINVA. O planejamento só passou a integrar suas atividades após aprovação na X Conferência Interamericana de uma Resolução, a de número XXXV, que regulamentou tal ampliação de escopo. Nessa ocasião,

los gobiernos acordaron asignarle al Centro un caráter permanente e incluir en su programa de trabajo atividades de planeamento, por lo cual la institución deberá llamarse en el futuro Centro Interamericano de Vivienda y Planeamiento. (VIVIENDA..., 1957, p. 11)

Uma vez enunciadas essas redes institucionais que são os objetos da investigação e antes de avançar numa abordagem mais elaborada sobre as mesmas, convém retomar alguns dos argumentos e indagações de Devés (2014), em especial a sua compreensão sobre icomo y por qué se formanlas redes?, pois a resposta complementa a explicação sobre o que seria uma rede. Para o autor, "las tensiones entre voluntad y espontaneidade, entre cuestiones propriamente académicas y otras no tanto, se encuentran en el origen y evolución de las redes". (DEVÉS, 2014, p. 30)

Essa indagação é importante, pois permeia um processo que tem relação estreita com as redes interamericanas de planejamento acima apresentadas, que é o da institucionalização das redes como entidades que, de alguma forma, foram organizadas segundo regulações que especificavam sua própria existência e campo de atuação. Ao mesmo tempo em que se perguntou como se formam as redes, formulou-se a ideia de que todo esse processo culminaria numa institucionalização, que se estruturaria em sociedades, centros, associações, congressos e publicações, com a qual, por outro lado, Marta Casaús Arzú (2014, p. 26) apresentou um contraponto numa determinada passagem do 298 prólogo de sua autoria que acompanha o livro Redes intelectuales en 
America Latina: hacia la constitución de una comunidade intelectual. $\mathrm{O}$ contraponto é sobre a ideia de Eduardo Devés (2014, p. 26) de que as redes "tuvieron una escassa duración, debido a su informalidade, a su escassa profesionalización como intelectuales".

Esse contraponto foi antecedido pelo reconhecimento de um grande acerto de Devés (2014) ao apontar o movimento fundacional das redes intelectuais quem orbitaram o circuito intelectual do uruguaio José Enrique Rodó e seu livro Ariel (decorrendo daí a rede arielista), publicado em 1900, em grande medida estruturantes da chamada “geração hispano-americana de 1998". Foi nesse momento em que ocorreu o que ela definiu como uma "quiebra de una corriente positivista, liberal y racista", gerador de uma busca da identidade latino-americana através do "humanismo espiritualista, del vitalismo y del espiritualismo socialista o anarquista”. O questionamento ao enunciado de Devés sobre a escassa informalidade de algumas redes como responsáveis pela sua pouca duração foi assim formulado:

No obstante, a mi juicio, eso fue lo que las hizo constituirse en auténticas redes, construídas por lazos y relaciones tangibles e intangibles, de interconcexiones e intercâmbios de bienes y servicios, con vínculos densos o laxos, sin necesidad de institucionalizaciones ni formalizaciones de ningún tipo, porque de lo contrario en esse momento pasarían a convertirse en outra cosa: organizaciones, instituciones, grupos formales. (ARZÚ, 2014, p. 26)

Esse argumento de Casaús Arzú parece indicar que a ideia basilar de funcionamento de uma rede perderia seu sentido quando institucionalizada, dado que a informalidade é o que tornaria a rede mais autêntica, constituída por laços mais sólidos. Portanto, o seu oposto, qual seja, tudo aquilo que caminhou para algum processo de institucionalidade não poderia ser categorizado e historiografado nos termos conceituais que a maioria dos autores citados opera em suas pesquisas sobre as redes. Essa questão é relevante ao estudo que estou desenvolvendo, pois é justamente essa institucionalização em sociedades ou associações o grande escopo de investigação - que será considerada na segunda parte do texto - sobre aquelas instituições interamericanas que atuaram no âmbito do planejamento urbano-regional, cada uma delas 
com uma especificidade que a particulariza no concerto das múltiplas redes intelectuais e profissionais forjadas no continente americano durante o século XX: de escritores, de economistas, de arquitetos, de urbanistas, de planejadores, entre tantas outras.

No entanto, e felizmente, para salvaguarda das contradições das ideias e das diversidades das concepções - em especial num mundo em que verdades absolutas e totalizantes parecem ressurgir das cinzas das mais abomináveis narrativas de ódio e de preconceitos -, reconhece Marta Casaús Arzú (2014, p. 26) que

aqui entraríamos en un largo debate entre la consideración de redes formales e informales, fragmentos de red, bloques de red, en donde no existe un critério unánime acerca de lo que se entende por red y el valo teórico-metodológico que cada corriente utiliza en sus análisis.

E preservada essa contradição das ideias ao reconhecer que não existe uma unanimidade, é ela que fundamenta, nesses termos, o entendimento de que as organizações, as instituições, os grupos formais conformaram redes de profissionais planejadores urbanos e assim também estão sendo estudadas.

Dito de outra forma, acredito que, no âmbito historiográfico da arquitetura, do urbanismo e do planejamento urbano, o entendimento é de que a institucionalização foi uma característica estrutural que ora antecedeu, ora resultou do próprio movimento e atuação dos profissionais. Uma institucionalização que também deve ser interpretada num duplo sentido ou dupla ocorrência: as instituições compatibilizaram suas atividades autonômicas numa ideia de "rede interna" ao mesmo tempo em que suscitaram uma "articulação entre redes" - e neste caso, justamente a partir da interlocução e circulação dos profissionais que transitaram entre as instituições ou participaram das atividades que eram realizadas, mas especialmente os congressos, publicações e reuniões técnicas. Ou seja, a formação de redes institucionalizadas no campo da arquitetura, do urbanismo e do planejamento urbano-regional não é um dado conjuntural, mas 300 uma característica estrutural - e não menos sólida ou autêntica, como 
formulado por Arzú (2014, p. 30) - de complexos e diversos campos profissionais constituídos, como afirmou Devés, por um "conjunto de personas ocupadas en la producción y difusión del concocimiento, que se comunican en razón de su actividad professional".

Dito isso, compreende-se que a própria concepção sobre a rede, sobre suas características, vínculos e toda produção dela emanada dependerá daquilo que se defina ou escolha como o objeto de estudo: no âmbito dos historiadores das ideias, algumas das diversas redes já estudadas, entre elas, as redes arielista e cepalina (trabalhadas por Eduardo Devés) e as redes intelectuais centro-americanas (trabalhadas por Marta Casaús Arzú); ${ }^{5}$ no âmbito da história da arquitetura e do urbanismo, por exemplo, a rede dos Congressos Pan-americanos de Arquitetos (trabalhadas por Fernando Atique), a rede do Rotary (trabalhada por Margareth Pereira) e a rede austral (investigada por Jorge Francisco Liernur); e no âmbito da história do planejamento urbano-regional, o conjunto de redes que venho pesquisando, organizadas com profissionais originários dos campos da economia, do direito, da arquitetura e do urbanismo, da engenharia, do planejamento e das ciências sociais, que, de alguma forma, dialogaram e se articularam na órbita do pensamento municipalista em relação ao desenvolvimento urbano-regional dos municípios em suas mais variadas dimensões: habitação, infraestrutura, serviços urbanos, transportes etc.

Neste ponto da argumentação, é necessário enunciar outras perguntas: seria, então, possível pensar numa rede municipalista interamericana? E se foram redes que operaram nessa dimensão interamericana, como problematizar a dimensão cultural e política da América Latina? O que diferenciaria a dimensão interamericana da latino-americana nos campos da arquitetura, urbanismo e planejamento urbano? Quais as relações e interlocuções que os profissionais desses campos tiveram com o debate político, ideológico e cultural marcadamente assimétrico entre os interesses dos Estados Unidos da América (EUA) e dos demais países do continente durante o século XX - e desde o século XIX - ${ }^{6}$ e em suas diversas ocorrências, como a Guerra Fria, a Revolução Cubana, a Operação Pan-americana, as ditaduras militares latinas etc.? Nos campos da arquitetura, urbanismo e planejamento 
urbano-regional, existiram redes latino-americanas ou todas elas se circunscreveram ao contexto espacial-cultural interamericano, incluídos os profissionais dos EUA? Ou ainda, as redes nacionais que porventura se formaram e estabeleceram relações internacionais estavam articuladas com o contexto latino-americano e/ou interamericano?

As possíveis respostas a essas perguntas não podem ser simplificadoras, menos ainda determinadas por procedimentos analíticos calcados apenas na dualidade contraposta entre a dominação imperialista dos EUA e a submissão dos países latino-americanos, inclusive no campo das ideias sobre os problemas urbanos e regionais dos municípios do continente. E ao fazer essa ressalva, não pretendo diminuir, anular ou deixar de reconhecer que a contraposição e a assimetria nas relações políticas, econômicas e culturais - também na cultura profissional urbanística - ao longo dos séculos XIX e XX existiram e também foram prejudiciais aos países latino-americanos. $\mathrm{O}$ que pretendo é escapar a uma determinação ideológica que tudo explicaria nessas relações pelo imperialismo e pela absorção-importação das concepções dos americanos do Norte (e dos europeus), não restando nada aos profissionais das Américas Central e do Sul e dos países caribenhos que não fosse aceitar naturalmente essa determinação e aplicá-las em seus países e cidades.

E justamente porque a história (urbana), como campo de investigação, precisa desnaturalizar os eventos e abrir espaço em suas explicações às contradições e aos papéis políticos e técnicos que os profissionais latino-americanos também exerceram é que o percurso interpretativo precisa ser continuamente repensado para ele mesmo não corroborar com essas determinações. Nesses termos, a investigação deve iluminar as ideias dos urbanistas e planejadores latino-americanos no processo de construção do conhecimento, produzido e divulgado nos diversos ambientes institucionalizados nesse ambiente interamericano. E mais, partindo do pressuposto de que a construção das ideias ocorre num jogo complexo de "[...] disputas por el poder o por el capital sócio-cultural” (DEVÉS, 2014, p. 35); portanto, a análise não deve ser concordante com certa naturalização de que o lugar dos 302 latino-americanos é aquele plasmado pela recepção. 
No fundo, é também um procedimento que se estrutura ideologicamente, pois, justamente, quer reconhecer e compreender as concepções urbanísticas e urbano-regionais, desde o sul e centro do continente, na produção das ideias estruturantes das diversas atividades realizadas pelas redes interamericanas de planejamento. Nesse sentido, como contraponto não apenas à determinação explicativa pelo imperialismo, mas à historiografia (inclusive latino-americana) que ainda estrutura suas conceituações e explicações com base na importação das ideias, que só seriam possíveis de serem forjadas pelo Norte civilizado, seja ele Europa ou EUA. Em sentido diametralmente oposto a essa concepção (reducionista), as considerações de Marta Casaús Arzú, na parte inicial de seu prólogo sobre o livro de Eduardo Devés, enunciam o esforço de parte da historiografia latino-americana em construir uma narrativa desvencilhada de certas amarras explicativas:

representa un esfuerzo de sínteses entre las diferentes corrientes de pensamento que se han desarrollado en la región a lo largo del siglo XX, desvelando que dicho pensamento há sido novedoso y creativo [...] y además, há influído en Europa más de lo que se há venido considerando hasta ahora. Outra novedad de este libro es el análisis metodológico de las redes [...] como estructuras generadoras de discurso y poder en América Latina, pero tambien como redes creadoras de pensamento furte y de creacción de una identidade nacional, regional y nacional [...] al reconstruir los fragmentos de redes intelectuales a lo largo de la historia política e intelectual latino-americana, lo que pone de manifiesto es la existência de un pensamento continental, de um proyecto de identidade latino-americana o ibero-americana, en el que las coincidências y los planteamientos comunes son más frecuentes que las dissidências o los desencuentros y en donde, contrariamente a lo que se há venido afirmando en otros libros de historia de las idea o del pensamento latino-americano, resulta falsa la creencia de que no habia um pensamento próprio. (ARZÚ, 2014, p. 22)

Por tudo isso é que a dimensão interamericana de análise não surge de uma deliberação externa às redes que estão sendo estudadas. O fundamento dessa opção está, de um lado, pautado na própria caracterização de cada uma das instituições no momento em que foram 
criadas, todas elas como instituições interamericanas, assim como foram os Congressos Pan-americanos de Arquitetos já mencionados. Por outro lado, pela documentação já catalogada, diversa em suas origens institucionais e complexa naquilo que são os temas tratados em cada documento. Ou seja, o "interamericano" não é o reconhecimento de um protagonismo assimétrico dos profissionais anglo-americanos em relação aos latino-americanos, mas o entendimento de que, nessa assimetria, é possível investigar invertendo o olhar interpretativo metaforicamente tal qual o mapa político e cultural "América invertida" proposto pelo artista uruguaio Joaquim Torres García.

E para tornar ainda mais complexa a análise dessa trama das redes interamericanas, é preciso considerar um processo de articulação não só interamericano, mas também ibero-americano, especificamente pelos vínculos estabelecidos entre a OICI e o Instituto de Estudios de Administración Local (IEAL), criado na Espanha em 1940. ${ }^{7}$ Os vínculos começaram a se estreitar mais enfaticamente a partir de 1955, com o I Congresso Iberoamericano de Municípios, realizado em Madrid, ${ }^{8}$ depois consolidados em 1976, na ocasião do I Congresso Extraordinário de Municípios realizado pela OICI em Montevidéu, no Uruguai, quando inclusive mudou seu nome de Organización Interamericana para Organización Iberoamericana, mudando também a abrangência de sua atuação. E uma vez constatadas essas articulações intercontinentais, não se pode negligenciar que se conformou, no século XX, um movimento em três escalas espaço-culturais: ibero-americano, interamericano e nacional; neste caso, para os países onde os profissionais também se organizaram em instituições. Por hora, a explicação será delineada pela segunda dessas escalas, a interamericana, que é o espaço político e cultural originário das instituições interamericanas de planejamento urbano-regional com foco no desenvolvimento municipal.

\section{As INSTITUIÇÕES COMO UMA CONSTRUÇÃO CULTURAL: UM PROJETO INTERAMERICANO}

No transcorrer das primeiras cinco décadas do século XX, o continente 304 experimentou os sinais do intenso, crescente e acelerado processo 
urbanização, acompanhado de importantes transformações econômicas decorrentes, em grande parte, da expansão da industrialização. Nesse contexto, ocorreram ações públicas marcadas por investimentos de caráter social, especialmente no campo da habitação e da infraestrutura urbana. Os governos nacionais de alguns países da América Latina também encaminharam ações que buscavam a articulação entre os planos de desenvolvimento numa dimensão produtiva macroeconômica e ações mais diretamente relacionadas às cidades. Dois casos latinoamericanos singulares desse processo foram as propostas para Brasília, no Brasil, e Ciudad Guayana, na Venezuela.

Esses fatos e ações favoreceram o surgimento de novas experiências e discussões no campo do urbanismo e do planejamento urbano-regional, muitas delas resultantes da interlocução profissional e institucional ocorrida em todo o continente americano. Em certa medida, é possível considerar que as instituições interamericanas surgiram para indicar alternativas ao desenvolvimento dos países e seus municípios; portanto, são também produto de um dado momento histórico marcado por importantes mudanças sociais, econômicas e urbano-regionais que, especialmente, a América Latina vivenciou entre 1900 e 1950.

A ideia de produto associada ao recorte temporal não está, entretanto, construída no sentido naturalizado, como se, historicamente, as instituições necessariamente teriam que ter existido. Está pensada como resultante de complexos e contraditórios processos de urbanização, industrialização, crescimento urbano, metropolização e todas as demandas intramunicipais e interregionais que tais fatores acarretaram; ao mesmo tempo em que foram pensadas intelectual e institucionalmente por seus atores como caminho necessário para a construção de proposições para esse ambiente continental em transformação. E assim como a ideia de uma construção cultural proposta por Adrián Gorelik (2005, p. 112) para pensar a cidade latino-americana - que "não pode ser tomada, então, como uma realidade natural" -, as instituições que foram formuladas para apresentar "soluções" para as problemáticas dessa cidade devem ser investigadas como parte dessa construção. Ou seja, "[...] como parte de um projeto histórico completo e coerente, no interior do qual talvez tenha sido formulada, 
com maior intensidade, a ideia de América Latina como projeto" (GORELIK, 2005, p. 117) e que, na pesquisa que estou desenvolvendo, será considerado em sua dimensão interamericana, e não somente latino-americana.

As instituições são parte desse projeto e, ao mesmo tempo, aquilo que manteve a realidade urbano-regional latino-americana em permanente projeto-projeção de futuro, especialmente a partir da década de 1960. Nessa década, os caminhos projetados na década anterior (1950), quiçá antes, foram pavimentados, percorridos e toda uma complexa rede de instituições nacionais também foram criadas em paralelo às instituições interamericanas supranacionais (ou não governamentais). Como exemplo, a Oficina Central de Coordinación y Planificación (1958), o Centro de Estudios del Desarrollo (1960), a Sociedad Venezolana de Planificación, todas na Venezuela; a Superintendência de Desenvolvimento do Nordeste (1959), o Serviço Federal de Habitação e Urbanismo/Banco Nacional da Habitação (1964-1965), a Sociedade Brasileira de Planejamento (1968), todas no Brasil; o Ministério de Vivienda y Urbanismo (1965) do Chile, entre tantas outras, todas elas criadas como instituições dos estados nacionais.

Esse conjunto de instituições abriria ainda a possibilidade de compreensão daquela "construção" a partir dos profissionais que transitaram em duas "escalas institucionais", quais sejam, a escala institucional nacional e a escala institucional supranacional, que foram as instituições interamericanas. Um caminho interessante de interpretação a partir desse duplo movimento é o de saber se as discussões nacionais entrariam na pauta do debate continental e viceversa, fomento análises-estudos comparativos pelos profissionais entre as especificidades do desenvolvimento das nações para a elaboração de um projeto geral.

A primeira instituição criada no continente nesse sentido foi a OICI, no ano de 1938, em Cuba. Sua existência está atrelada à construção do pensamento municipalista interamericano, cujas origens estão relacionadas ao movimento pan-americanista ${ }^{9}$ forjado nas Conferências 306 Internacionais Interamericanas (DULCI, 2008) a partir de 1889, 
sendo esse contexto histórico-político a base estrutural de criação da Organização dos Estados Americanos (OEA) na década de 1940. A primeira Conferência Interamericana ocorreu em Washington entre outubro de 1889 e abril de 1890, seguida das seguintes realizações: a II, realizada no México entre 1901 e 1902; a III, no Brasil em 1906; a IV, na Argentina em 1910; a V, no Chile em 1923; a VI, em Cuba no ano de 1928; a VII, no Uruguai em 1933; a VIII, no Peru em 1938; a IX, na Colômbia em 1948, quando foi criada a OEA; ${ }^{10}$ e a X, na Venezuela em 1954.

O primeiro indicativo de que a criação da OICI estava em gestação se deu na VI Conferência Interamericana, realizada em Cuba no ano de 1928, ao ser aprovada pela Resolução no 47, a realização do primeiro congresso pan-americano de municípios para discutir os temas do urbanismo e da administração municipal. Conforme os pontos dessa resolução, ficou resolvido que

1. Que por la Unión Panamericana se organice y lleve a efecto el Primer Congreso Panamericano de Municipios.

2. Que en el programa de ese Congreso se inscriban con la mayor amplitud los temas que afectan al urbanismo y a los sistemas de administración urbana, así como aquellos otros que directa o indirectamente se relacionen con la vida comunal.

3. Que para concurrir a ese Congreso se invite a los Municipios mayores de cincuenta mil habitantes, así como a las organizaciones municipales políticas o técnicas y a las personas de reconocida competencia en la materia fundamento del Congreso.

4. Que siguiendo la práctica estableada por la Unión Internacional de Ciudades se efectúe una reunión preparatoria del Congreso en cuestión, gestionándose por la Unión Panamericana que esa junta previa tenga efecto en la ciudad de Boston, en el primer semestre de 1930, aprovechando la circunstancia de que en ese año celebra la culta ciudad norteamericana el tercer centenario de su fundación. 5. Y que el Primer Congreso Panamericano de Municipios tenga efecto en la ciudad de la Habana, en las fechas que se indiquen durante el primer semestre de 1931, en razón de ser la capital cubana la que ha llevado a cabo los principales trabajos por la intermunicipalidad. (CONGRESO..., 2013) 
A segunda manifestação dessa gestação está na Resolução no 70 do Primer Congreso Panamericano de Municipios, efetivamente realizado em 1938, também celebrado na capital cubana. Dessa Resolução nº 70, veio a determinação do caráter de permanência "a la cooperação intermunicipal y a las atividades em prol del mayor estrechamiento de relaciones entre los pueblos americanos a través de la intermunicipalidad”. (REVISTA MUNICIPAL INTERAMERICANA, 1950, p. 2) As temáticas urbanísticas também estiveram na pauta da VII Conferência, realizada em Montevidéu no ano de 1933, quando foi aprovada resolução que recomendou às "Repúblicas americanas que eneltrazado, edificación y renovación de las ciudades, tengam especialmente encuentalos fatores de orden social, económico e higiénico que se relacionan con la vivenda". (UNIÓN PANAMERICANA, 1958, p. 8)

Outro encaminhamento importante decorreu da Resolução no 35, aprovada na X Conferência (realizada na Venezuela em 1954), ao referendar a decisão do Consejo Interamericano Economico y Social (CIES) - em sua Resolução no 15/56, aprovada dia 12 de abril de 1956 - de convocar a Primera Reunión Tecnica Interamericana en Vivienda y Planeamiento. O temário dessa Primeira Reunião Técnica foi aprovado pelo CIES no dia 30 de agosto de 1956, constando dois grandes blocos: o primeiro, "La vivenda de interes social en los países de America"; e o segundo, "Acción, coordinación y cooperación técnica interamericana en el campo de la vivenda y del planeamento". (UNIÓN PANAMERICANA, 1958b, p. 125) No momento da aprovação desse temário geral, o CIES reafirmou a importância que a habitação de interesse social teve na X Conferência Internacional Interamericana, quando se reconheceu que esse assunto "es uno de los más importantes para el Continente", tendo sido analisado "tanto en su aspecto urbano como en el rural”. (UNIÓN PANAMERICANA, 1958b, p. 125)

Essa Reunión Técnica Interamericana en Vivienda y Planeamiento de 1956 teve ainda um papel simbólico e político importante para a consolidação das redes institucionais e profissionais que atuavam no campo do urbanismo e do planejamento urbano no continente americano. Paralelamente aos trabalhos previstos e realizados na Reunião Técnica, ocorreu a oficialização da SIAP. Nesse caso específico, a 308 partir de um tema fundamental debatido na ocasião de sua origem 
intelectual: a formação dos profissionais planejadores e o ensino do planejamento na América Latina. Essa origem intelectual da SIAP ocorreu em Porto Rico, no mês de março de 1956, quando se realizou um Seminário sobre Formación de Personal para la Planificación Urbana y Regional. No encerramento do seminário, formou-se uma comissão ad hoc - presidida pelo portorriquenho Rafel Picó -, cujos trabalhos resultaram na criação jurídica da SIAP em Bogotá, no mesmo ano de 1956, durante a já mencionada Primera Reunión Técnica Interamericana en Vivienda y Planeamiento, promovida e coordenada pela Unión Panamericana/OEA. ${ }^{11}$

\section{A FORMAÇ̃̃O PROFISSIONAL: UMA SINCRONIA INTELECTUAL NAS REDES INTERAMERICANAS?}

O Seminário de Porto Rico foi organizado conjuntamente entre a OEA e a ONU, em parceria com a Junta de Planificación de Puerto Rico, a Escuela de Administración de la Universidad de Puerto Rico e o Departamento de Estado y Hacienda del Estado Libre de Puerto Rico. Nessa ocasião, estiveram presentes representantes do Brasil, Argentina, Canadá, México, Peru, Uruguai, Cuba, Porto Rico, Inglaterra, Panamá e Estados Unidos, que debateram as relações entre o planejamento físico e o desenvolvimento econômico e social, a formação de planejadores e o papel das instituições de pesquisa na América Latina. ${ }^{12}$ (CAMACHO, 2007; NACIONES UNIDAS, 1957) Nessa ocasião, Anatole Solow apresentou, como informe das atividades da OEA, um panorama sobre a realidade urbano-industrial latino-americana:

En America Latina se está produciendo un rápido dessarrollo económico, acompanhado de un ritmo acelerado de industrialización, lo cual implica un incremento de la población, movilidad y notable crecimiento urbano [...] En el processo de desarrollo se producen gradualmente câmbios que son interdependientes. No pueden aplazarse los efectos dinâmicos del crecimiento económico sobre el ambiente físico y social de la comunidade [...] Las ciudades de América Latina están creciendo a un ritmo cada vez más acelerado y seguirán desarrollandose 
en proporción directa al avance de la industrialización y al desenvolvimiento de los respectivos países. Existe un rápido desplazamiento de la población rural hacia los núcleos urbanos que crea cada mayor congestión en el centro y mayor confusión en su periferia [...] En los últimos 20 años la proporción de la población urbana respecto de la total ha aumentado del $25 \%$ al $40 \%$. De mantenerse este ritmo, dentro de 30 años la populación urbana podría llegar a constituir un $60 \%$ de la total. Además, gran parte de este incremento se presenta en las zonas metropolitanas de ciudades mayores de 1000.000 habitantes, de las cuales hay ya 62 en Améric Latina [...] sin embargo, las ciudades crecen sin una adecuada planificación y esto se traduce en servicios municilaes deficientes, escacez de viviendas y falta de continuidade en el processo de renovación urbana [...] Todos estos problemas demandan urgente solución. Pero, son contadas e insuficientes las instituciones de formación y escasos los profesionales dedicados a la planificación urbana y regional en América Latina. (NACIONES UNIDAS, 1957, p. 82)

No entendimento dos profissionais presentes nesse seminário realizado em Porto Rico, a pauta intelectual sobre o planejamento urbano e regional deveria fundamentar as ações necessárias para atuar nessa complexa realidade urbano-industrial. Uma concepção importante decorrente foi a de que a articulação-relação entre as escalas nacional e local deveria ocorrer pela região e pelo planejamento regional. A defesa dessa concepção foi apresentada na abertura das sessões do Seminário sobre Formación de Personal para la Planificación Urbana y Regional pelo Arquiteto Ernest Weissman, à época, subdiretor da Diretoria de Assuntos Sociais da ONU.

[...] la región constituye el eslabón fundamental entre la camunidad local y la nación. Una planificación regional facilita la identificación de los objetivos nacionales emfunció de la acción local. Em otras palavras, la planificación regional constituye el cuadro adecuado dentro del cual los proyectos de dessarrollo, tanto de alcance nacional como de caráter local, pueden encontrar su equilíbrio y su próprio lugar. ${ }^{13}$ (NACIONES UNIDAS, 1957, p. 6) 
A contribuição do Brasil a esse seminário foi apresentada por Helio Modesto, que proferiu a conferência "Los problemas de la planificación en el Brasil", de certa forma reproduzindo parte central dos seus próprios argumentos e críticas sobre ausência de planejamento no país e que já haviam sido publicados nas revistas municipalistas do Instituto Brasileiro de Administração Municipal (IBAM) e Associação Brasileira dos Municípios (ABM). Segundo Helio Modesto (1957, p. 95):

[...] contamos con planes de desarrollo físico, planes sociales y económicos, pero se encuentran aislados entre sí y funcionan como fines em sí y no como médios para alcanzar un objetivo; la mayor parte de ellos facasa precisamente por esta ausencia de interrelación. Entre los administradores no existe una mentalidade y una consciência de planificación que reconozca el hecho de que los problemas de la comunidade sólo puden enfocarse en conjunto, si se desea aprovechar plenamente los medios disponibles para su solución. La creacción de esta mentalidade propicia es la medida más importante que deben adoptar quines se interesan por el futuro del país. El mejor medio de lograrlo es la acción educativa en problemas de planifiación.

Se essa crítica de Helio Modesto foi feita a partir de um contexto nacional específico, o Brasil, a base do argumento também permeou outras considerações, como as formuladas por Luis Lander - à época, ex-ministro de Obras Públicas da Venezuela e assessor da Junta de Planificación de Puerto Rico - para toda a América Latina. Na sua conferência "Evolución futura de la planificación en la América Latina”, foi incisivo na crítica sobre o equívoco em relação ao que deveria ser a "planificación":

Muchas personas en América Latina pueden crer en la planificación, pero lamentablemente la mayoria de ellas sinceramente cree que están planificando simplemente porque preparan planes para la construcción de carreteras o para el mejoramiento físico de uma ciudad (un equivalente del movimento para emellecer la ciudad), o para la edificación de escuelas, hospitales o casas o porque planifican ciertos aspectos de su economia [...] Desearía que en América Latina existiera outro tipo de planificación, una 
planificación integral que abarque el desarrollo adecuado de todos los recursos discponibles para el mejoramiento de las condiciones de vida de la población. Esto es planificación general, en la cual se tienen em cuenta los aspectos económicos, sociales y físicos en un desarrollo equilibrado. (LANDER, 1957, p. 94)

Outro ponto relevante das discussões do seminário, certamente o mais importante, e sobre o qual Helio Modesto e Luis Lander também coadunaram em suas posições, foi sobre a proposição de escolas para formação de planejadores. Em todas as outras conferências, muito se discutiu sobre as características dessa formação, sobre as escolas implementadas no Ocidente - desde a primeira experiência na Inglaterra, no ano de 1909, com uma cátedra de desenho urbano na Universidade de Liverpool,$-{ }^{14}$ sobre critérios para o exercício da profissão de planejador, sobre a relação da planificação com a sociologia e outros assuntos relativos ao tema, mas apenas os dois foram mais incisivos na proposição de que se criassem escolas "regionales de planificación para estudiantes postuniversitarios" (Helio Modesto) ou de um "Instituto Latinoamericano de Planificación, no sólo para la formación professional de técnicos, sino también para educar al pueblo en esta cuestión” (Luis Lander). Ao final do seminário, uma reunião entre os membros organizadores locais, a ONU e a OEA foi realizada para debater as possibilidades de criação de uma escola de planejamento na América Latina, que seria localizada em Porto Rico (também foi definida como sede da SIAP) em função dos seguintes pontos:

a) Puerto Rico es partidário de la planificación general y coordenada que alienta y pone em práctica; b) su Junta de Planificación desempeña sus funciones en forma excelente y durante los años há logrado merecidamente el respecto y la cooperación del Pueblo y de todos los órganos y entidades del Gobierno; c) há formado un ambiente favorable, um espécie de laboratório, ideal y practico a la vez, que se necessita para la formación de planificadores competentes [...] Aunque la escuela sería de carácter nacional, se considero que por razones geogtráficas podría dar formación professional a estudiantes de otros países, especialmente de la región del Caribe, y de otros países de América Latina. (KAYANAN, 1957, p. 12) 
Na parte da documentação publicada pela ONU com as conclusões do Seminário sobre Formación de Personal para la Planificación Urbana y Regional, não consta a indicação de que uma escola seria ou foi efetivamente criada, apenas referência à mencionada reunião. Nos seis temas da conclusão - importancia de la planificación en el desarrollo económico y social; escala regional de la planificación; la formación de planificadores; plan de estudios; instituciones de investigación y de enseñanza de la planificación en la América Latina; cooperación y acción internacional -, desenvolvidos em 27 tópicos, também não constam informações claras sobre isso, apenas considerações mais genéricas sobre a necessidade de relacionar o planejamento urbanístico com aspectos do planejamento econômicos e social e de equilibrar o ensino prático e teórico do planejamento.

Esse cenário indefinido e generalista das conclusões do seminário não muda o fato de que uma instituição de ensino já havia sido criada pela OEA em 1951, o CINVA (dirigido pela División de Vivienda y Planeamiento da Unión Panamericana/OEA), no âmbito dos programas de cooperação técnica no 22, desenvolvido pelo CIES. Como informado por Anatole Solow - ao descrever as atividades da OEA direcionadas ao fomento da educação no campo do planejamento urbano e regional -,

[...] El Centro Interamericano de Vivienda tiene como missión proporcionar instrucción y capacitación práctica a profesionales de todos los países americanos que deseen especializarse en los aspectos tecnológicos, económicos, sociales y administrativos de la vivenda. (SOLOW, 1957, p. 82)

Na sequência dos seus argumentos, fez menção ao Projeto n 23 do mesmo Programa de Cooperción Técncia da OEA, cujo objetivo seria o "estabelecimiento de institutos para la enseñanza e investigación especializada del urbanismo y la planificación” baseados na necessidade de "estabelecer centros de estuidos postuniversitarios de planificación donde se formen los especialistas”. (SOLOW, 1957, p. 83)

As informações apresentadas por Anatole Solow (1957) a partir do Programa de Cooperação Técnica da OEA parecem indicar algum 
contraponto à ideia de um centro único e sediado em Porto Rico, tal qual a proposta nesse sentido inserida nas conclusões do Seminário sobre Formación de Personal para la Planificación Urbana y Regional. Na sequência dos seus argumentos, ele formulou justamente uma defesa dos centros menores, ou centros regionais de estudos, ou seja, praticamente a mesma ideia levantada por Helio Modesto. Segundo Anatole,

En vez de crear una instiuición central única, se considero más conveniente y práctico aydar al establecimiento de centros más pequenos que presten servicio a grupos más reducidos de países, sobre bases más homogêneas y definidas [...] Se há considerado más factible comenzar gradualmente, dentro de un plan continental, con un centro, estableciendo luego otros dos más com carácter regional. En esta forma podría desarrollarse por etapas um programa de largo alcance que incluiria las seguientes atividades: a) cursos de planificación urbana y regional [...] b) trabajos de investigación complementados con períodos de servicio en organizaciones especializadas; c) asesoría técnica; d) cursillos sobre planificación en universidades de los diferentes países. (SOLOW, 1957, p. 83)

Anatole Solow (1957) ainda clamou pelo respeito à Resolução n⿳ 35 da X Conferência Internacional Interamericana, por ser o órgão supremo da OEA e na qual se decidiu que o CINVA teria caráter permanente e que era fundamental fortalecer sua ação e, somente quando as circunstâncias assim justificassem, que organismos similares sejam criados em outros países do continente. Por outro lado, isso não deveria significar, pelas palavras de Anatole, impedimento ao incentivo e fomento de instituições de ensino previamente existentes nos diversos países do continente para atuação numa escala mais regional. Para ele, dever-se-ia apenas respeitar a referida Resolução no 35 e que funcionassem como subcentro do CINVA, estabelecido fora da Colômbia e numa instituição que tivesse condições de oferecer os serviços necessários ao bom funcionamento do ensino do planejamento urbano e regional.

Terminada a Conferência de Porto Rico e com o desenvolvimento das 314 atividades da SIAP após sua fundação jurídica em Bogotá, no mesmo 
ano de 1956, quando também ocorreu sua Primeira Assembleia, somente em 1958 é que o debate sobre o ensino e a formação de planejadores foi tratado oficialmente. Nesse ano, ocorreu em Huampaní, no Perú, a Segunda Reunión Técnica Interamericana en Vivienda y Planeamiento, UniónPanamericana/OEA, ocasião em que a SIAP realizou sua Segunda Assembleia. Surgiu, nesse evento, a adoção, como parte da proposta programática da SIAP, o auxílio ao trabalho de uma possível missão técnica sobre educação do planejamento. A proposta foi analisada por sua junta diretiva, que aprovou a Missão e, em seguida, solicitou apoio à Fundação Ford, ONU e OEA para que fosse colocada em prática. $\mathrm{O}$ apoio foi acertado e a Missão iniciou seus trabalhos durante a realização do Congresso Mundial de Planificación - celebrado em San Juan de Puerto Rico -, entre os dias 28 de maio e 3 de junho de 1960, tendo concluído os trabalhos em setembro do mesmo ano.

A Missão foi formada por três membros - Cesar Garcés (Colômbia), José Vera (Chile) e Humberto Espinoza (Panamá) - assessorados por Rafael Picó (Porto Rico), Francis Violich (EUA) e John Blandford (EUA), cujos trabalhos resultaram no Informe de la Misión para la Enseñaza de la Planificaciónen América Latina. Esse documento foi organizado em três partes específicas, denominadas, respectivamente: "La situación en Latinoamerica, subdesarrollo, planificación y ensenñaza"; "Estado actual de la enseñanza de la planificación en latinoamerica"; "Estado actual de la planificación en latinoamerica". (SOCIEDAD INTERAMERICANA DE PLANIFICACIÓN, 1960) A Missão visitou dez países: Argentina, Chile, Colômbia, Costa Rica, Porto Rico, México, Panamá, Peru, Venezuela e Brasil. E para ficar apenas com a etapa da Missão que ocorreu no Brasil, o levantamento realizado concluiu que existem duas escolas de administração pública (EBAP e IBAM), duas de economia, três de arquitetura, duas de engenharia, nenhuma de planejamento e o que entrou na categoria "outras", o Centro de Estudos e Pesquisas Urbanísticas da USP, que, para a Missão, foi uma das duas instituições da América Latina que avançou na "colaboración Interdisciplinaria" 15 em relação aos diversos aspectos do desenvolvimento da nação, da região e dos municípios. ${ }^{16}$ (SOCIEDAD INTERAMERICANA DE PLANIFICACIÓN, 1961) 
A análise preliminar desses e outros documentos produzidos no âmbito da OEA e da ONU a partir da década de 1950 revela, e com uma considerável densidade nos debates, o reconhecimento das instituições e dos profissionais sobre a importância do planejamento na solução dos problemas e demandas decorrentes da intensa urbanização nos países latino-americanos e do continente americano no seu conjunto. Tanto é assim que, anos antes desse seminário em Porto Rico, ocorreu a primeira ação mais efetiva em relação à formação de planejadores: em 1951, a Comisión de Asuntos Sociales da ONU reconheceu a necessidade de organização de informações sobre o tema, tendo solicitado aos seus membros que facilitassem o acesso à documentação. A justificativa dessa solicitação aos países menos desenvolvidos estava no reconhecimento pela ONU de que a "planificación podia desempenhar un papel importante ensudesarrollo económico y social". (NACIONES UNIDAS, 1957, p. 1) A partir dessa primeira iniciativa e até o início da década de 1960, a ONU organizaria importantes encontros internacionais para discutir os temas do desenvolvimento urbano e regional, urbanização, habitação social, mas também incorporaria a pauta da formação profissional.

Entre eles, o Seminário Regional sobre Vivienda y Mejora de la Comunidad en Asia y el Lejano Oriente, realizado em Nova Delhi em 1954; um seminário sobre urbanização em Bangkok, no mês de agosto de 1956, organizado conjuntamente com a Organização das Nações Unidas para a Educação, a Ciência e a Cultura (UNESCO) e o Governo da Tailândia; uma conferência sobre "Planificación del Dessarrollo Urbano y Rural em Trinidad", no mês de novembro de 1956, quando se reforçou a ideia de que a "planificación está vinculada com los factores econômicos, sociales y físicos de la vida de la comunidade". (NACIONES UNIDAS, 1957, p. 1) Desses encontros, o que foi realizado em Bangkok enunciou, mais explicitamente em sua conclusão, as relações intrínsecas entre planejamento urbanístico e planejamento econômico, assim como a necessidade de formação de profissionais:

[...] la planificación del médio físico es tan sólo uno de los aspectos del processo de dessarrollo económico y social...y, al igual que toda forma de planificación, es un processo continuo 
cuya eficácia sólo puede estar assegurada por un organismo que tenga la competência, la autoridade legal y los recursos financieros necesarios [...] Es indispensable, por conseguiente, crear un organismo encargado de la planificación, capacitar al personal que le es necesario y fijar sus métodos y procedimientos de acción. (NACIONES UNIDAS, 1957, p. 1)

Assim como a ONU, a OEA também promoveu encontros com a participação de profissionais e instituições de vários países para discussão sobre os diversos assuntos decorrentes e relacionados ao intenso processo de urbanização que se consolidava desde o início do século XX no continente americano. O que talvez diferencie o trabalho da OEA em relação à ONU é que sua atuação mais específica no continente americano avançou no sentido da criação de instituições originárias de resoluções daquelas Conferências Internacionais Interamericanas (das quais a OEA surgiu), de seus programas de cooperação técnica ou seminários especializados que promoveu. Entre esses seminários, cuja documentação foi localizada e catalogada no processo de pesquisa em desenvolvimento, é possível mencionar a Primeira e Segunda Reuniões Técnicas Interamericanas em Vivienda y Planeamiento, realizadas, respectivamente, em Bogotá (1956) e Huampaní, no Perú (1958); o Seminario de Ténicos y Funcionarios en Planeamiento Urbano, realizado em Bogotá (1958); e os três Seminários Regionales de Asuntos Socieales - Vivienda y Urbanismo, realizados em Quito, San Salvador (ambos no mesmo ano de 1950) e Porto Alegre (1951), ${ }^{17}$ e que são a base documental pesquisada até aqui sobre parte das atividades das instituições, em especial da OICI e da SIAP.

Se até aqui foram apresentadas a OICI e a SIAP como instituições criadas no continente americano nessa primeira metade do século $\mathrm{XX}$, uma terceira amplia esse arcabouço institucional, ainda que pensada inicialmente como um programa de atividades, e não uma instituição como as duas primeiras: o CINVA, ${ }^{18}$ criado em 1951. Com atuação inicial circunscrita ao tema da habitação, teve origem na implementação, pela Unión Panamericana, do Projeto 22 do Programa de Cooperação Técnica da Organização dos Estados Americanos. (UNIÓN PANAMERICANA, 1957) Nesse sentido, sua origem está, como a OICI, intrinsecamente associada às Conferências 
Internacionais Americanas, por serem elas a origem da própria OEA e de seus órgãos, especialmente a División de Vivienda y Planeamiento - do Departamento de Asuntos Econômicos y Socieles da Unión Panamericana -, cuja organização e estrutura funcional estavam relacionadas aos assuntos do planejamento urbano e da habitação, sendo esta a quarta instituição em estudo, ainda que até o presente momento não tenha avançado muito.

Conforme organograma da estrutura funcional do CINVA, publicado no Informe Anual de 1953, sua estrutura de funcionamento estava organizada em três grandes áreas de atuação: estudos técnicos, estudos socioeconômicos e intercâmbio científico. (UNIÓN PANAMERICANA, 1953) Especialmente as duas primeiras áreas esclarecem a concepção do Centro em relação aos problemas e soluções no campo da habitação: compreensão social e econômica definida a partir das necessidades locais das comunidades, articulação entre o projeto arquitetônico e tecnologias construtivas das habitações e sua integração urbana, que eram abordadas nos cursos de formação de profissionais. ${ }^{19}$ Como mencionado, ocorreu mudança ${ }^{20}$ desse foco inicial do Cinva na habitação de interesse social, ao ser incorporado o planejamento em seu nome e atribuições. Essa mudança colocou o Cinva em consonância estreita com a OICI e com a SIAP, ao mesmo tempo em que explicitou o reconhecimento da OEA sobre a importância do planeamento urbano e regional, sobre a cooperação intermunicipal e a necessidade de formação de profissionais para atuar nas mais diversas áreas do planejamento para o desenvolvimento dos países e dos municípios numa concepção que não era mais a do urbanismo como projeto.

Nesse sentido, a criação dessas instituições na primeira metade do século XX reflete muito do contexto intelectual que permeava os debates - em congressos, nas revistas, nas assessorias e estudos sobre urbanização, planificação, habitação, desenvolvimento econômico e planejamento regional no continente americano realizados por profissionais como Francis Violich, Anatole Solow, Eduardo Montoulieu, Lloyd Rodwin, Ernest Weissmann e Rafael Picó. A presença de profissionais brasileiros que atuavam nos campos do 18 urbanismo e do planejamento urbano-regional e que mantiveram 
vínculos com esse ambiente institucional-intelectual não pode ser desconsiderada. Entre outros, é possível mencionar os nomes de Antonio Bezzera Baltar, Antonio Delorenzo Neto, Helio Modesto, Osmar Cunha, Diogo Lordello de Melo e Henry Cole, cujas interlocuções com as redes e instituições interamericanas indicavam a interlocução de algumas instituições brasileiras, entre elas, a ABM, o IBAM, o Serviço Federal de Habitação e Urbanismo (SERFHAU) e a Sociedade Brasileira de Planejamento (SBP), esta com origem vinculada à SIAP.

\section{Algumas CONSIDERAÇÕES FINAIS}

Essa conjunção institucional e profissional possibilitou a formação de uma ampla e diversa trama de redes intelectuais cujos trabalhos estavam focados nas análises das condições urbano-regionais de todo o continente americano, ainda que substancialmente dedicados à realidade latino-americana. Desse ambiente institucional e profissional, também se formularam proposições para solução das problemáticas decorrentes do intenso processo de urbanização e industrialização que os países latino-americanos experimentavam naqueles anos de 1950 e que se tornariam ainda mais complexos na segunda metade do século.

Por tudo isso é que as instituições (OICI, SIAP, CINVA e División de Vivienda y Planejamento e Unión Panamericana - DVP/UP) estão sendo investigadas como estruturantes de um projeto interamericano que teve relevante participação dos campos disciplinares da arquitetura, do urbanismo, do direito, da economia e do planejamento para pensar e propor soluções ao desenvolvimento municipal. Entre as proposições e discussões já levantadas, é possível destacar aquelas que relacionam o planejamento e o desenvolvimento, inclusive como parte dos propósitos mais específicos da SIAP: a regionalização para fins de planejamento, a coordenação do desenvolvimento mediante instrumentos do planejamento integral, a institucionalização e a prática do planejamento para implementação de políticas sociais nos níveis nacional, provincial e municipal e, por fim, a institucionalização do ensino do planejamento. 
Colocando analiticamente em diálogo todo esse movimento de construção intelectual e no período de 1930 a 1960, é possível afirmar que existiu uma "contraposição entre o que era divulgado sobre a produção sul-americana na Europa e EUA, e o que de fato era discutido pelos profissionais locais em fóruns, congressos e revistas, no continente sul-americano". (GOMES, 2009, p. 8) Da mesma forma, deve-se levar em conta que, em meados dos anos 1930 e 1940, o continente ainda era relativamente ignorado dentro da perspectiva analítica histórica urbana e arquitetônica, centrando-se apenas na Europa e EUA. (GOMES, 2009) A atuação dessas redes interamericanas integrou esse movimento de contraponto a partir de três eixos mais gerais: os congressos, as revistas e, por fim, atividades de consultoria e pesquisa, como a que foi organizada sobre "La enseñanza de la planificación em la América Latina”, cujo relatório foi apresentado por Rafael Picó e Francis Violich em setembro de 1960.

Essa ampla divulgação da produção dos profissionais e sua projeção em âmbito internacional foram também importante impulso ao processo de institucionalização do urbanismo e do planejamento na América Latina. Da mesma forma, para a criação de fóruns de discussão profissional que viabilizaram a interlocução de planejadores e responsáveis públicos sobre os problemas de urbanização em suas diversas facetas, mas especialmente habitação e planos urbanos. Crescia, portanto, a importância de agregá-los em sociedades profissionais para a troca de experiências em questões de interesse comum aos países do continente. A SIAP, a OICI, a DVP e o CINVA são, portanto, produto e catalizadores desse processo, todos eles responsáveis por publicações, realização de congressos e atividades de consultoria.

Nesse contexto interinstitucional, os projetos editoriais tiveram papel relevante para compreensão e divulgação de estudos sobre os problemas urbanos e a urbanização, de um modo geral. Particularmente, a revistas contribuíram para a divulgação para fora das fronteiras territoriais do continente americano dos estudos e realizações em pauta. Ou seja, as revistas especializadas, desde as revistas de arquitetura dos anos 1930 até as revistas mais envolvidas com as questões de urbanização e planejamento, tais como a revista interamericana 320 da SIAP ou a revista municipal interamericana da OICI, buscavam 
apresentar os problemas urbanos enfrentados pelos países, bem como apresentar soluções para as diversas necessidades de um continente, que experimentava forte processo de urbanização e crescimento demográfico. Da mesma forma, não se descuidou do processo de formação profissional, seja no campo da arquitetura e da produção da habitação - como foi, inicialmente, o papel do CINVA -, seja no campo do planejamento urbano e regional - como foi o caso da SIAP. Tanto que, já a partir da década de 1930, um tema constante em todas essas publicações foi a consolidação e regulamentação da profissão de arquiteto, algumas vezes combinado com a preocupação com a formação profissional. (GOMES, 2009)

A partir da década de 1940, as revistas especializadas de arquitetura e planejamento da América passaram a dar maior importância aos temas correspondentes ao urbanismo e a gestão urbana. Um caso importante de discussão nessas áreas ocorreu a partir da necessidade de reconstruir a Cidade de San Juan, na Argentina, destruída por um terremoto em 1944. Surgiram debates urbanísticos locais que geraram uma série de discussões sobre o planejamento multidisciplinar na América Latina, estimulado por publicações em revistas sul-americanas, mas de abrangência internacional, como a Nuestra Arquitectura e a American Forum. Todo esse debate permite uma consideração importante sobre o próprio campo disciplinar: "de certa forma, essa série sinaliza claramente um deslocamento de interesse das questões propriamente urbanísticas em direção àquelas relacionadas ao planejamento de caráter multidisciplinar". (GOMES; ESPINOZA, 2009, p. 26)

Acompanhando esse processo de mudanças originários nas décadas de 1930 e 1940, o Boletim Planificación y Desarrollo e a Revista Interamericana de Planificación, ambos publicados e editados sob a coordenação da SIAP a partir da década de 1960, divulgaram artigos relacionados ao planejamento multidisciplinar. Foram abordadas questões de interesse comum aos países da América Latina, bem como algumas análises de casos específicos para serem estudados em outros contextos locais. Correspondiam, portanto, a questões intimamente ligadas à situação de planejamento e urbanização da América Latina e que buscavam soluções integradas em todos os 
níveis de planejamento - econômico, social, urbanístico e, já nesta época, ambiental. Ou seja, se tem algo que essas redes profissionais realizaram foi a produção de conhecimento, tal qual enunciado por Eduardo Devés (2014) como elemento estrutural para afirmar que uma rede intelectual se conformou, ainda que tal conhecimento tenha sido anulado ou intencionalmente esquecido pelas forças especulativas do capital internacional. O resultado desse "esquecimento": as nossas cidades continuam sendo tratadas como instrumento de produção e reprodução dos interesses financeiros e as imagens que permanecem são as da precária periferização, violência urbana, degradação ambiental e especulação imobiliária "construindo" cidades fissuradas. 


\section{NOTAS}

1 Pesquisa financiada pelo Conselho Nacional de Desenvolvimento Científico e Tecnológico (CNPq), bolsa de produtividade e universal, 2014/2017-2018.

2 O primeiro estudo, "Para outra história urbana: Interdisciplinaridade e intertextualidade no estudo da cidade de Ribeirão Preto", foi publicado na revista Registros, em 2003 (como resultante das primeiras aproximações que fiz ao campo historiográfico à época do mestrado). O segundo: "Velázquez e Veyne, e as articulações entre a pintura e a história: os processos relacionais na constituição da origem dos eventos históricos”, foi publicado na revista Mosaico, em 2009.

3 Importante fazer referência aos estudos de Jorge Francisco Liernur sobre a "Red Austral”, publicados em 2008, como contribuição fundamental ao estudo das redes profissionais, ainda que mais centrados na investigação sobre a produção arquitetônica e urbanística e não tanto pelo campo do planejamento urbanoregional. No caso brasileiro, considero a pesquisa sobre a rede do Rotary Club Internacional e os primórdios do urbanismo no Brasil, desenvolvida por Margareth da Silva Pereira (2011), um exemplo importante. Ver o artigo publicado na revista Oculum Ensaios: <http://periodicos.puc-campinas.edu.br/ seer/index.php/oculum/article/view/138>.

4 Tendo como base a conferência inaugural que proferi no II Seminário Urbanistas e Urbanismo no Brasil (IAU/USP, 2015), elaboreio artigo "O urbanismo e os urbanistas na história urbana brasileira: percursos e perguntas para pensar a história urbana da América Latina”, que foi publicado na revista Risco, para também tecer algumas considerações que dialogam e pactuam com esse diagnóstico crítico. Está disponível em: 〈https://www.revistas.usp.br/risco/ article/view/127418>.

5 Como sugestão para uma primeira aproximação ao trabalho de Marta Casaús, ver "Las redes intelectuales centroamericanas y sus imaginarios de nación (18901945)", em <http://www.ortegaygasset.edu/publicaciones/circunstancia/ ano-iii--numero-9---enero-2006/investigaciones-en-curso>, e o livro Las redes intelectuales centroamericanas: un siglo de imaginarios nacionales (1820-1920), de 2005, publicado em parceria com Tereza García Giráldez.

6 Em relação ao século XIX, no bojo do processo político que envolveu a defesa da independência política das colônias espanholas por Simón Bolívar, o Congresso do Panamá de 1826, o Congresso de Jurisconsultos de 1877 e a Conferência Internacional Interamericana em 1889. Como o objetivo específico deste projeto não é debate político e internacional no âmbito das relações comerciais e diplomáticas sobre o pan-americanismo, não faremos detalhamentos sobre o tema. Autores especializados em história das relações exteriores já produziram importantes trabalhos, entre eles: Morgenfeld (2011), Silva (2009) e Dulci (2008). 
7 Em dois trabalhos já desenvolvidos (um publicado e o outro em publicação), foi possível abordar mais diretamente o contexto espanhol e suas relações com os profissionais e instituições do continente americano: "Urbanismo e municipalismo na Espanha: entre o Estatuto Municipal e a Unión de Municipios Españoles na década de 1920”, publicado na Revista Brasileira de Estudos Urbanos e Regionais; e "Urbanismo e municipalismo na Espanha: Ieal e a articulação Iberoamericana para o desenvolvimento municipal”, que está em publicação pela revista Zarch: Journal of Interdisciplinary studies in Architecture and Urbanism.

8 Na sequência desse I Congresso Iberoamericano de Municípios, que ocorreu em Madrid, vieram os Congressos de Lisboa (1959), Brasília (1965), Barcelona (1967), Santiago do Chile (1969). Importante frisar que esses congressos não tinham relação com os Congressos Interamericanos de Municípios realizados pela OICI desde 1938. São mesmo dois eventos distintos que contaram com a participação de profissionais vinculados a duas instituições.

9 Esse movimento pan-americanista tinha como objetivo básico a "união das nações americanas por meio do fortalecimento e do comércio na América”. (DULCI, 2008, p. 2)

$10 \mathrm{Na}$ IX Conferência Internacional Americana, realizada em Bogotá, foi definida a Carta de la Organización de los Estados Americanos com a definição dos seus conselhos; entre eles, o Conselho Interamericano Econômico e Social. Como será desenvolvido na sequência, a criação do CINVA integrou as atividades de cooperação técnica da OEA.

11 Segundo informe incluído no Relatório Final da Primera Reunión Tecnica Interamericana en Vivienda y Planeamiento, a SIAP celebrou sua assembleia constitutiva e aprovou seu estatuto. A comissão organizadora da SIAP presente nessa reunião técnica era formada por Rafel Picó, Cándido Oliveras e Luis Lander. (UNIÓN PANAMERICANA, 1958b)

12 Oficialmente criada em Bogotá, no dia 5 de dezembro de 1956, durante a Primera Reunión Tecnica Interamericana en Vivienda y Planeamiento, organizada e realizada pelo CIES da OEAs. A secretaria do CIES era o Departamento de Assuntos Econômicos e Sociais da União Pan-americana, da qual a División de Vivienda y Planeamiento faz parte.

13 Essa discussão sobre o planejamento regional nesse contexto das redes interamericanas está em desenvolvimento, especialmente a partir do estudo da trajetória profissional-intelectual de Antonio Delorenzo Neto, que dirigiu o Instituto de Estudos Municipais da Escola de Sociologia e Política de São Paulo. O referido instituto organizou, sob a coordenação de Delorenzo Neto, o I Seminário Interamericano de Estudos Municipais, em 1958, como parte das atividades do Congresso Interamericano de Municípios que ocorreu no Rio de Janeiro no mesmo ano. Um primeiro estudo foi publicado nos Anais do Encontro 
e Regional (ENANPUR) de 2013, realizado em Recife. Antonio Delorenzo Neto teve importante atuação nesse contexto interamericano, especialmente na OICI, como representante da Associação Brasileira de Município. Ver em: <http://anpur.org.br/project/anais-do-xv-ena/>.

14 Informação apresentada por FrederickJ. Adams, do Departamento de Planificación Urbana y Regional do Instituto de Tecnologia de Massachusetts (MIT), na conferência "Situación de la planificación y de suenseñanza". (ADAMS, 1957, p. 41)

15 A outra foi o Centro de Planificación Económica da Universidad de Chile. (SOCIEDAD INTERAMERICANA DE PLANIFICACIÓN, 1960)

16 O exemplo utilizado pela Missão para essa interpretação foi o "Estudo para o desenvolvimento do litoral norte do Estado de São Paulo”, desenvolvido com a colaboração de economistas, engenheiros e arquitetos. O nome de Anhaia Mello não apareceu nessa referência.

17 Esse seminário foi realizado no Rio Grande do Sul, com a participação de duas instituições brasileiras com atuação no campo da habitação: a Fundação da Casa Popular e o Departamento de Habitação Popular da Prefeitura do Distrito Federal, nesse momento chefiada pela engenheira Carmem Portinho, além de outras repartições públicas. As informações sobre esses seminários foram publicadas, em 1952, no Informe Final organizado pela Unión Panamericana.

18 O nome original era Centro Interamericano de Vivienda. Como será ainda explicado, a partir de 1954, receberá o nome de Centro Interamericano de Vivienda y Planeamiento, CINVA.

19 Jorge Alberto Rivera Paez, El CINVA: un modelo de cooperación técnica, 19511972, 2002. Outras importantes pesquisas foram realizadas sobre o CINVA, entre elas: Peña Rodriguez, El programa CINVA y la acción comunal: construyendo ciudad a través de la participación comunitária (2010). Para alguns pesquisadores colombianos, entre eles, Jorge Alberto Rivera Paez, o programa geral do CINVA deu prioridade a uma série de experiências interdisciplinares e interprofissionais, assim como ao trabalho empírico e de articulação direta com a comunidade. Da mesma forma, esse programa geral enfatizou uma prática não ortodoxa da arquitetura e do planejamento urbano na América Latina, que, para Rivera Paez, estava em contraste com as práticas passíveis de reconhecimento das contradições derivadas da difusão e aceitação sem críticas dos encaminhamentos e proposições do contexto da Arquitetura Moderna preconizada pelos CIAM no continente.

20 Resolução no 35 da X Conferência Internacional Interamericana, realizada na Venezuela, no ano de 1954, após análise de proposições apresentadas pelas delegações da Colômbia, Brasil e Venezuela. Pela resolução, o Centro Interamericano de Vivienda foi denominado de Centro Interamericano de Vivienda y Planeamiento. 


\section{REFERẼNCIAS}

ADAMS, F. J. Situación de la planificación y de suenseñanza. In: NACIONES UNIDAS. Departamento de Asuntos Económicos y Sociales. Formación de personal para la planificación urbana y rural: seminario sobre formación de personal para la planificación urbana y rural. Puerto Rico, marzo de 1956. Nueva York, 1957.

ARZÚ, M. E. C. Las redes intelectuales centroamericanas y sus imaginarios de nación (1890-1945). Circunstancia, Madrid, ano 3, n. 9, enero 2006. Disponível em: <http://www.ortegaygasset. edu/publicaciones/circunstancia/ano-iiim-numero-9--menero-2006/ investigaciones-en-curso>. Acesso em: 20 mar. 2015.

ARZÚ, M. C. Prólogo. In: DEVÉS, E. Redes Intelectuales en América Latina: Hacia la constitución de una comunidade intelectual. Santiago de Chile: Instituto de Estudos Avançados, 2014.

ARZÚ, M. E. C.; GIRÁLDEZ, T. G. Las redes intelectuales centroamericanas: un siglo de imaginarios nacionales (1820-1920). Guatemala: F \& G editores, 2005.

BRESCIANI, M. S. M. A construção da cidade e do urbanismo: ideias têm lugar? In: FREITAS, J. F; MENDONÇA, E. M. S. A construção da cidade e do urbanismo: ideias têm lugar? Vitória: EDUFES, 2012. p. 141-160.

CAMACHO, L. Sociedad Interamericana de Planificación, SIAP 50 años Vida institucional y programática. Revista Bitácora Urbano Territorial, Colombia, p. 268-284, v. 1, n. 11, 2007.

CONGRESO Panamericano de Municipios (Sexta Conferencia Internacional Americana, La Habana - 1928). [S.1.], 2013. Disponível em: <http://www.dipublico.org/14467/congreso-panamericano-demunicipios-sexta-conferencia-internacional-americana-la-habana-1928/>. Acesso em: 20 mar. 2015.

DEVÉS, E. Redes Intelectuales en América Latina: Hacia la constitución de una comunidade intelectual. Santiago de Chile: Instituto de Estudos 326 Avançados, 2014. 
DULCI, T. M. S. As Conferências Pan-americanas: identidades, união aduaneira e arbitragem (1889 - 1928). 2008. 134 f. Dissertação (Mestrado em História) - Faculdade de Filosofia, Letras e Ciências Humanas, Universidade de São Paulo, São Paulo, 2008.

DULCI, T. M. S. Conferências Panamericanas (1889-1928): a questão das identidades. In: ENCONTRO INTERNACIONAL DA ANPHLAC, 8., 2008, Vitória. Anais Eletrônicos... Vitória: ANPHLAC, 2008.

FARIA, R. S. Para outra história urbana: Interdisciplinaridade e intertextualidade no estudo da cidade de Ribeirão Preto. Registros, Plata, ano 1, n. 1, p. 163-175, nov. 2003.

FARIA, R. S. de. Sobre la Primera Reunion Técnica Interamericana em Vivienda y Planeamiento. Washington: Pan American Union, 1958.

FARIA, R. S. de. Urbanismo e desenvolvimento municipal na Europa: os congressos municipalistas da Unión de Municipios Españoles.

Ciudades, Valladolid, n. 19, 2016a. Disponível em: <http://www3.uva.es/ iuu/CIUDADES/Marcos_R.htm>. Acesso em: 10 out. 2015.

FARIA, R. S. de. Urbanismo e municipalismo na Espanha: IEAL e a articulação Ibero-americana para o desenvolvimento municipal. ZARCH: Journal of Interdisciplinary Studies in Architecture and Urbanism, Zaragoza, n. 6, p. 206-219, 2016b. Disponível em: <http://zarch.unizar. es/index.php/es/>. Acesso em: 15 out. 2017.

FARIA, R. S. de. Urbanismo e municipalismo na Espanha: entre o Estatuto Municipal e a Unión de Municipios Españoles na década de 1920. Revista Brasileira de Estudos Urbanos e Regionais, Recife, v. 17, n. 1, p. 105- 122, 2015. Disponível em: <http://www.anpur.org.br/ publicacao/arquivos/20160517100357Volume_17__numero_1.pdf >. Acesso em: 15 out. 2017.

FARIA, R. S. Velázquez e Veyne, e as articulações entre a pintura e a história: os processos relacionais na constituição da origem dos eventos históricos. Revista Mosaico, Goiânia, v. 2, n. 1, p. 26-34, jan./jun. 2009.

FUSCHINI, G. A. La rede de escritores latinoamericanos en los años sessenta. UNIVERSUN, [S.1.], n. 15, p. 337-350, 2000. 
GOMES, M. A. Urbanismo na América do Sul: circulação de ideias e constituição do campo, 1920-1960. Salvador: EDUFBA, 2009.

GOMES, M. A. F., ESPINOZA, J. C. H. Olhares cruzados: visões do urbanismo moderno na América do Sul, 1930-1960. In: GOMES, M. A. Urbanismo na América do Sul: circulação de ideias e constituição do campo, 1920-1960. Salvador: EDUFBA, 2009. p. 13-41.

GORELIK, A. A produção da 'cidade latino-americana. Tempo Social, São Paulo, v. 17, n. 1, p. 111-133, 2005.

KAYANAN, A. C. Antecedentes, organización y procedimentos del Seminario. In: NACIONES UNIDAS. Seminário sobre formación de personal para la planificación urbana y rural. Nueva York, 1597.

LANDER, L. Evolución futura de la planificación en América Latina. In: NACIONES UNIDAS. Formación de personal para la planificación urbana y rural. Nueva York, 1957. p. 94-95.

MODESTO, H. Los problemas de la planificación em Brasil. In: NACIONES UNIDAS. Formación de personal para la planificación urbana y rural. Nueva York, 1957. p. 95-98

MORGENFELD, L. A. Vecinos en conflito: Argentina frente a Estados Unidos en las conferencias pan-americanas 1880-1955. Buenos Aires: Continente, 2011.

NACIONES UNIDAS. Formación de personal para la planificación urbana y rural. Nueva York, 1957.

PEÑA RODRIGUEZ, M. L. El programa CINVA y la acción comunal: construyendo ciudad a través de la participación comunitária. Bogotá: Universidad Nacional de Colombia, Faculdad de Artes, 2010. (Colección Punto Aparte).

PEREIRA, M. da S. Localistas e cosmopolitas: a rede do Rotary Club International e os primórdios do urbanismo no Brasil (1905-1935). Oculum Ensaios, Campinas, n. 13, p. 12-31, jan./jun. 2011.

PINHEIRO, E. P. Circulação de ideias e academicismo: os projetos 32 8 urbanos para as capitais do Cone Sul, entre 1920 e 1940. In: GOMES, 
M. A. F. Urbanismo na América do Sul: circulação de ideias e constituição do campo, 1920-1960. 1. ed. Salvador: EDUFBA, 2009. p. 119-149.

REVISTA MUNICIPAL INTERAMERICANA. La Habana: Comision Panamericana de Cooperacion Intermunicipal, año I, n. $1 / 2$, jul./dic. 1950 .

SOCIEDAD INTERAMERICANA DE PLANIFICACIÓN. Informe de la Misión para la Enseñaza de la Planificaciónen América Latina. San Juan, Jul./ set. 1960. Manuscrito digitalizado.

SOCIEDAD INTERAMERICANA DE PLANIFICACIÓN. La Enseñanza de la planificación en America Latina. San Juan, 1961.

SOLOW, A. Acción de la OEA dirigida a estimular la educación en planeamento urbano y regional. In: NACIONES UNIDAS. Formación de personal para la planificación urbana y rural. Nueva York, 1957.p. 82-85.

SILVA, M.V. C. da. A defesa do pan-americanismo nas páginas de Américas. 2009. 141 f. Dissertação (Mestrado em Relações Internacionais) Universidade Estadual Paulista, São Paulo, 2009.

RIVERA PAEZ, J. A. El CINVA: un modelo de cooperación técnica, 1951-1972. 2002. Tesis (Maestria em História) - Departamento de Historia, Universidad Nacional de Colombia, Bogotá, 2002.

TOPALOV, C. Os saberes sobre a cidade: tempos de crise? Espaço $\mathbb{E}$ Debates, São Paulo, ano XI, p. 28-39, 1991.

UNIÓN PANAMERICANA. Departamento de Asuntos Economicos y Sociales. División de Vivienda y Planeamiento. Compilacion de Resoluciones sobre planieamiento, vivenda y edificación. Washington, 1958a.

UNIÓN PANAMERICANA. Departamento de Asuntos Economicos y Sociales. División de Vivienda y Planeamiento. Municipal Action for Housing Improvement and Slum Clearence. Washington, 1953.

UNIÓN PANAMERICANA. Departamento de Asuntos Economicos y Sociales de la Unión Panamericana. Vivienda y Planeamiento. Washington, 1957. n. 23. 
UNIÓN PANAMERICANA. Secretaria del Consejo Interamericano Económico y Social. Informe de la Secretaría del Consejo Interamericano Económico y Social sobre la primera reunión técnica interamericana en vivienda y planeamiento. Washington, 1958b.

WEISSNANN, E. Importancia de la formación de planificadores por la parte que desempeñan en el desarrollo económico y social. In: NACIONES UNIDAS. Formación de personal para la planificación urbana y rural. Nueva York, 1957. p. 19-21.

VIVIENDA \& planeamiento. Boletín da División de Vivienda y Planeamiento de la Unión Panamericana, [S.1.], p. 11, 1957. 